\title{
Effect of indomethacin on clinical progress and renal function in cystinosis
}

\author{
G B HAYCOCK, J AL-DAHHAN, R H K MAK, AND C CHANTLER
}

Evelina Children's Department, Guy's Hospital, London

SUMMARY Three children with nephropathic cystinosis were treated with indomethacin $3 \mathrm{mg} / \mathrm{kg}$ a day for periods ranging from 9 to 18 months. The drug produced worthwhile clinical improvement in all, with marked beneficial effects on polyuria, polydipsia, and general wellbeing. Clearance studies performed under conditions of maximal water diuresis showed that proximal tubular sodium reabsorption was increased in all children, with consequent reduction in sodium delivery to the distal nephron leading to reduced free water clearance and distal tubular cation exchange. Plasma sodium and potassium concentrations became normal in all patients, with improvement in phosphate and bicarbonate concentrations in one. Renal function continued to deteriorate, but without obvious acceleration of the process by the drug. We were unable to demonstrate a beneficial effect on growth; nevertheless, indomethacin is a useful adjunct to the symptomatic treatment of children with severe nephropathic cystinosis.

The specific metabolic defect underlying nephropathic cystinosis has not been identified, and no treatment has yet been shown convincingly to arrest, or even retard, the progression of the disease to end stage renal failure. ${ }^{1-3}$ Recent reports of a possible beneficial effect of cysteamine ${ }^{4-7}$ and phosphocysteamine ${ }^{8}$ must be regarded as preliminary and in need of confirmation by longer-term studies. Some palliation of the metabolic effects of the Fanconi syndrome is usually possible, and the judicious use of modern vitamin $D$ metabolites ${ }^{9} 10$ is certainly of benefit in the treatment of hypophosphataemic rickets; nevertheless, affected children rarely thrive and the results of symptomatic therapy are less than satisfactory, particularly as regards growth. Reports of the sodium- and waterretaining properties of prostaglandin synthetase inhibitors in various conditions ${ }^{11-14}$ prompted us to investigate the effects of indomethacin on renal function and clinical progress in 3 cystinotic children.

\section{Case reports}

Case 1. A girl, was investigated at age 4 years for long-standing polyuria, polydipsia, and hypokalaemia. The diagnosis of cystinosis was established by the finding of typical ophthalmoscopic and bone marrow appearances. Her growth was the least severely affected of the 3 patients at the time of diagnosis; at 4 years and 2 months her height was $97.5 \mathrm{~cm}$ and her weight $13.25 \mathrm{~kg}$. Her treatmen before the study was 6 effervescent potassium tablets daily and dihydrotachysterol $0.25-0.5 \mathrm{mg}$ daily. At the time of starting indomethacin she was found to be hypothyroid and L-thyroxine $0.1 \mathrm{mg}$ daily was given.

Case 2. Also a girl, failed to thrive from age 2 years with polyuria, polydipsia, and photophobia. Corneal and bone marrow examination confirmed the diagnosis of cystinosis when she was $3 \frac{1}{2}$. For the next 2 years she was treated with vitamin $D$ (calciferol) 6000-60000 units daily, a mixture of sodium and potassium citrate in varying doses, and energy supplements. L-thyroxine $0.1 \mathrm{mg}$ daily was added at 6 years 7 months. At entry into the study aged 5 years 11 months her height was $99 \mathrm{~cm}$ and her weight $13 \cdot 5 \mathrm{~kg}$.

Case 3. A boy, was the most severely affected child studied. Polyuria, polydipsia, and severe growth retardation began in the first year of life. During an episode of dehydration at age 14 months crystals were noted in the cornea, and characteristic bone marrow appearances were seen a little later. When first seen at Guy's Hospital aged 8 years 5 months his height was $91.4 \mathrm{~cm}$ and his weight $13.2 \mathrm{~kg}$. His 
treatment before the study was 1- $\alpha$-hydroxycholecalciferol $0.5 \mathrm{mg}$ daily, sodium bicarbonate $6 \mathrm{mmol}$, and potassium bicarbonate $6 \mathrm{mmol}$ four times daily. L-thyroxine $0.1 \mathrm{mg}$ was added at 8 years 11 months.

\section{Methods}

Each patient was studied twice, before and after 2 weeks' treatment with indomethacin $2-3 \mathrm{mg} / \mathrm{kg}$ a day, treatment being continued through the second study period. The following protocol was followed on both occasions.

Blood and urine samples were obtained at the beginning of the study for routine biochemistry and inulin blanks. After a bolus injection of $1 \mathrm{ml} / \mathrm{kg}$, a constant infusion of $10 \%$ inulin solution was maintained throughout the study at a rate calculated to give a plasma concentration of $25-35 \mathrm{mg} / 100 \mathrm{ml}$. A period of $30-40$ minutes was allowed for the inulin to equilibrate, during which water was administered in a dose of $600-800 \mathrm{ml} / \mathrm{m}^{2}$ body surface area to induce maximal water diuresis. The diuresis was maintained by replacing voided urine with equal volumes of water until the investigation was complete. Two or three consecutive 20-minute urine specimens were collected; the high rate of urine flow enabled all the children to comply with this requirement without difficulty. Heparinised blood specimens were obtained at the midpoint of each 20-minute collection period; constant inulin concentrations were achieved in all studies. Extracellular fluid volume expansion was then induced by the intravenous infusion of isotonic saline $20 \mathrm{ml} / \mathrm{kg}$ over $20-40$ minutes, after which two further timed urine and blood samples were obtained.

Inulin in plasma and urine was estimated by the method of Heyrovsky, ${ }^{15}$ modified for $10 \mu \mathrm{l}$ samples. Urine and plasma osmolality was measured by freezing point depression on an Advanced 3W osmometer. Plasma electrolytes were estimated by standard methodology using a Vickers multichannel automatic analyser.

$$
\begin{aligned}
& \begin{array}{ll}
\mathbf{C}_{\text {in }} & =\mathbf{U}_{\text {in }} \times \mathbf{V} / \mathbf{P}_{\text {in }} \\
\mathbf{C}_{\text {osm }} & =\mathbf{U}_{\text {osm }} \times \mathbf{V} / \mathbf{P}_{\text {osm }}
\end{array} \\
& \mathrm{C}_{\mathrm{Na}}=\mathbf{U}_{\mathrm{Na}} \times \mathrm{V} / \mathbf{P}_{\mathrm{Na}} \\
& \mathbf{c H}_{2} \mathrm{O}=\mathrm{V}-\mathrm{C}_{\text {osm }} \\
& \mathbf{F}_{\mathrm{Na}}=\mathbf{C}_{\mathrm{in}} \times \mathbf{P}_{\mathrm{Na}} \\
& \begin{array}{ll}
\mathrm{E}_{\mathrm{Na}} & =\mathrm{U}_{\mathrm{Na}} \times \mathrm{V} \\
\mathrm{DD}_{\mathrm{Na}} & =\mathrm{P}_{\mathrm{Na}} \times\left(\mathrm{C}_{\mathrm{Na}}+\mathrm{cH}_{2} \mathrm{O}\right)
\end{array} \\
& \mathbf{D R}_{\mathrm{Na}}=\mathrm{DD}_{\mathrm{Na}}-\mathbf{E}_{\mathrm{Na}} \\
& \mathbf{P R}_{\mathbf{N a}}=\mathbf{F}_{\mathbf{N a}}-\mathbf{D D}_{\mathrm{Na}} \\
& \mathbf{F P R}_{\mathbf{N a}} \%=\mathbf{P R}_{\mathbf{N a}} / \mathbf{F}_{\mathrm{Na}} \times 100 \\
& \mathrm{FDR}_{\mathrm{Na}} \%=\mathrm{DR}_{\mathrm{Na}} / \mathrm{F}_{\mathrm{Na}} \times 100 \\
& \mathrm{FE}_{\mathrm{Na}} \%=\mathrm{E}_{\mathrm{Na}} / \mathrm{F}_{\mathrm{Na}} \times 100
\end{aligned}
$$

$\mathrm{U}=$ urinary concentration, $\mathrm{P}=$ plasma concentration, $\mathrm{C}=$ clearance

\begin{tabular}{|c|c|c|c|c|c|c|}
\hline & \multirow[t]{2}{*}{ Case } & \multirow{2}{*}{$\begin{array}{l}\text { GFR } \\
(\mathrm{ml} / \mathrm{min} \text { per } 1 \cdot 73 \mathrm{~ms})\end{array}$} & $F N a$ & $P R N a$ & $D R N a$ & $E N a$ \\
\hline & & & \multicolumn{4}{|c|}{$(m E q / \min$ per $1.73 m s)$} \\
\hline \multirow{3}{*}{$\begin{array}{l}\text { Before treatment } \\
\text { Before volume expansion }\end{array}$} & & & & & & \\
\hline & $\begin{array}{l}1 \\
2 \\
3\end{array}$ & $\begin{array}{l}28 \\
27 \\
32\end{array}$ & $\begin{array}{l}3 \cdot 67 \\
3 \cdot 36 \\
3 \cdot 84\end{array}$ & $\begin{array}{l}1 \cdot 767(48) \\
2 \cdot 627(78) \\
2 \cdot 451(64)\end{array}$ & $\begin{array}{l}1 \cdot 134(30) \\
0.375(11) \\
0.621(16)\end{array}$ & $\begin{array}{l}0.773(21) \\
0.356(11) \\
0.764(20)\end{array}$ \\
\hline & & 29 & $3 \cdot 62$ & $2 \cdot 282(63)$ & $0.710(20)$ & $0.631(17)$ \\
\hline \multirow[t]{2}{*}{ After volume expansion } & $\begin{array}{l}1 \\
2 \\
3\end{array}$ & $\begin{array}{l}22 \\
27 \\
16\end{array}$ & $\begin{array}{l}2 \cdot 99 \\
3 \cdot 50 \\
1 \cdot 94\end{array}$ & $\begin{array}{l}1 \cdot 914(64) \\
2 \cdot 349(67) \\
0 \cdot 624(32)\end{array}$ & $\begin{array}{l}0.587(20) \\
0.699(20) \\
0.625(24)\end{array}$ & $\begin{array}{l}0.487(16) \\
0.447(13) \\
0.687(36)\end{array}$ \\
\hline & & 22 & $2 \cdot 81$ & $1 \cdot 629(58)$ & $0.637(23)$ & $0.541(19)$ \\
\hline \multicolumn{7}{|l|}{ During treatment } \\
\hline \multirow[t]{2}{*}{ Before volume expansion } & $\begin{array}{l}1 \\
2 \\
3\end{array}$ & $\begin{array}{l}15 \\
18 \\
25\end{array}$ & $\begin{array}{l}2 \cdot 00 \\
2 \cdot 33 \\
3 \cdot 26\end{array}$ & $\begin{array}{l}1 \cdot 613(81) \\
1 \cdot 663(71) \\
2 \cdot 164(67)\end{array}$ & $\begin{array}{l}0.243(12) \\
0.416(18) \\
0.661(19)\end{array}$ & $\begin{array}{l}0.148(7) \\
0.252(11) \\
0.490(15)\end{array}$ \\
\hline & & 20 & $2 \cdot 53$ & $1 \cdot 813(72)$ & $0.420(17)$ & $0 \cdot 297(12)$ \\
\hline \multirow[t]{2}{*}{ After volume expansion } & $\begin{array}{l}1 \\
2 \\
3\end{array}$ & $\begin{array}{l}23 \\
32 \\
22\end{array}$ & $\begin{array}{l}3 \cdot 09 \\
4 \cdot 26 \\
2 \cdot 83\end{array}$ & $\begin{array}{l}2 \cdot 189(71) \\
3 \cdot 236(76) \\
2 \cdot 223(79)\end{array}$ & $\begin{array}{l}0.576(19) \\
0.634(15) \\
0.359(13)\end{array}$ & $\begin{array}{l}0 \cdot 326(11) \\
0 \cdot 392(9) \\
0 \cdot 243(9)\end{array}$ \\
\hline & & 26 & $3 \cdot 39$ & $2 \cdot 549(75)$ & $0.523(15)$ & $0 \cdot 320(9)$ \\
\hline
\end{tabular}
concentration, in = inulin, $\mathrm{Na}=$ sodium, osm $=$ osmolality, $\mathrm{V}=$ urine flow rate, $\mathbf{F}_{\mathrm{Na}}=$ sodium filtration rate, $\mathrm{E}_{\mathrm{Na}}=$ sodium excretion rate, $\mathrm{DD}_{\mathrm{Na}}=$ rate of delivery of sodium to the distal nephron, $\mathbf{D R}_{\mathrm{Na}}=$ distal tubular sodium reabsorption rate, $\mathbf{P P}_{\mathrm{Na}}=$ proximal tubular sodium reabsorption rate. The $\mathrm{F}-$ prefix indicates 'fractional' - that is the proportion of the filtered load reabsorbed or excreted.

\section{Results}

Indomethacin reduced glomerular filtration rate (GFR) $\left(C_{\text {in }}\right)$ from a mean of 28.9 to $19.5 \mathrm{ml} / \mathrm{min}$

Table Renal tubular sodium handling before and during treatment with indomethacin

Figures in parentheses express the same quantities as percentage of filtered load.

$\mathbf{F}_{\mathrm{Na}}=$ filtered sodium, $\mathbf{P R}_{\mathrm{Na}}=$ proximally reabsorbed sodium, $\mathbf{D} \mathbf{R}_{\mathrm{Na}}=$ distally reabsorbed sodium, $\mathbf{E}_{\mathrm{Na}}=$ excreted sodium. 
per $1.73 \mathrm{~m}^{2}$; however, volume expansion largely reversed the fall to a mean value of 25.4. Mean absolute sodium excretion rate was reduced from 0.631 to $0.297 \mathrm{mEq} / \mathrm{min}$ per $1.73 \mathrm{~m}^{2}$ in the nonexpanded, and from 0.541 to 0.320 in the expanded, state. The changes in $\mathrm{Fe}_{\mathrm{Na}}$ were similar. $\mathrm{FPR}_{\mathrm{Na}}$ was greatly increased in both the expanded and the non-expanded state, while FDR $_{\mathrm{Na}}$ showed a small decrease. The full results are shown in the Table.

The effect of indomethacin on the reabsorption of water and sodium in the proximal tubular is illustrated in Fig. 1; at all levels of GFR the drug increased the proportion of the filtered load reabsorbed in this segment $(2 \mathrm{P}<\mathbf{0 . 0 1}$ for water; $2 \mathrm{P}<0.005$ for sodium). Fig. 2 shows the effect of indomethacin on distal tubular sodium reabsorption; a significantly greater proportion of the sodium
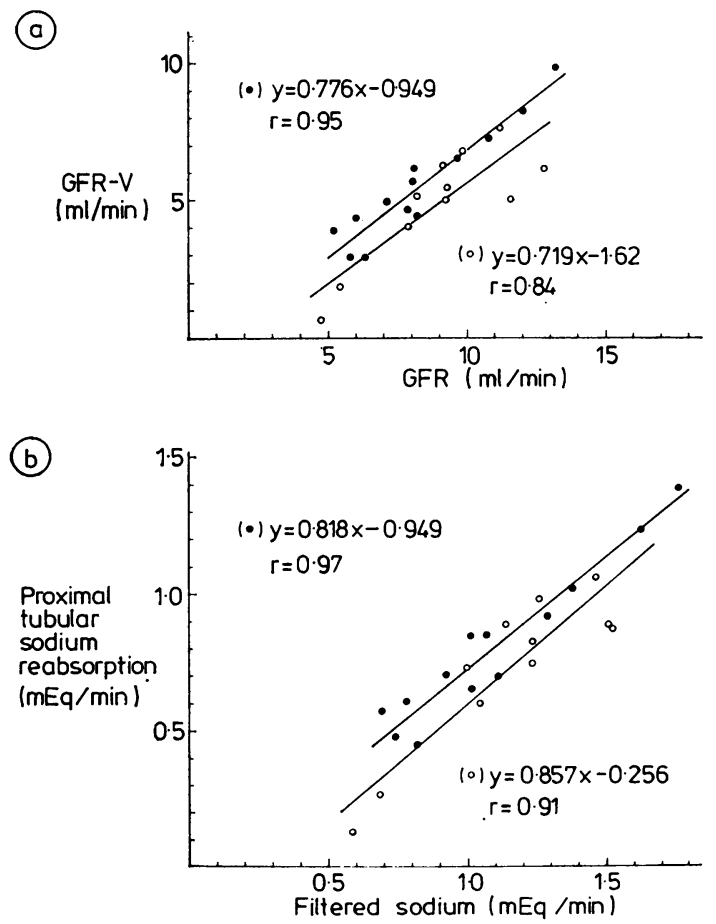

Fig. 1 (a) Calculated proximal tubular water reabsorption rate (GFR-V) plotted against GFR.

(b) Calculated proximal tubular sodium reabsorption rate plotted against sodium filtration rate. In each panel, the closed circles and the upper regression line represent values obtained on indomethacin, while the open circles and lower regression line represent values obtained off the drug. The vertical separation between each pair of regression lines is highly significant (upper panel, $2 P<0.01$; lower panel, $2 P<0.005)$.

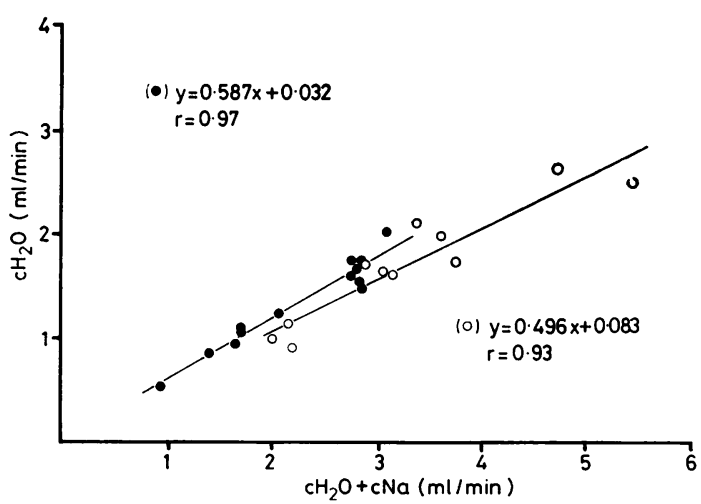

Fig. 2 Free water clearance plotted against the sum of free water clearance and sodium clearance. Symbols as in Fig. 1. The two regression lines are significantly separated $(2 P<0.02)$ although the slopes are not significantly different $(2 P>0 \cdot 2)$.

delivered to the distal nephron was reabsorbed in the presence of the drug than in its absence $(2 \mathrm{P}<0.02)$.

Plasma sodium and potassium concentrations were increased in all 3 children, as were those ofo phosphate and bicarbonate in the one child who had low values before the study (Fig. 3). All childrent showed an acute weight gain which averaged $7 \%$ of pretreatment weight.

All the children experienced clinical improvement. Polyuria, polydipsia, and salt craving were greatly reduced. Appetite increased in 2 patients but remained poor in the third. Increased wellbeing and energy were reported by all 3 families.

The effect of long-term treatment on renal function is shown in Fig. 4. Linear growth before and after the introduction of indomethacin is shown in Fig. 5.

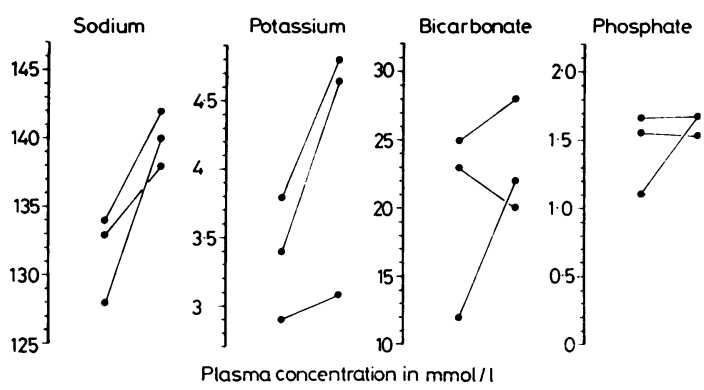

Fig. 3 Effects of 2 weeks' treatment with indomethacin on plasma electrolyte concentrations. 


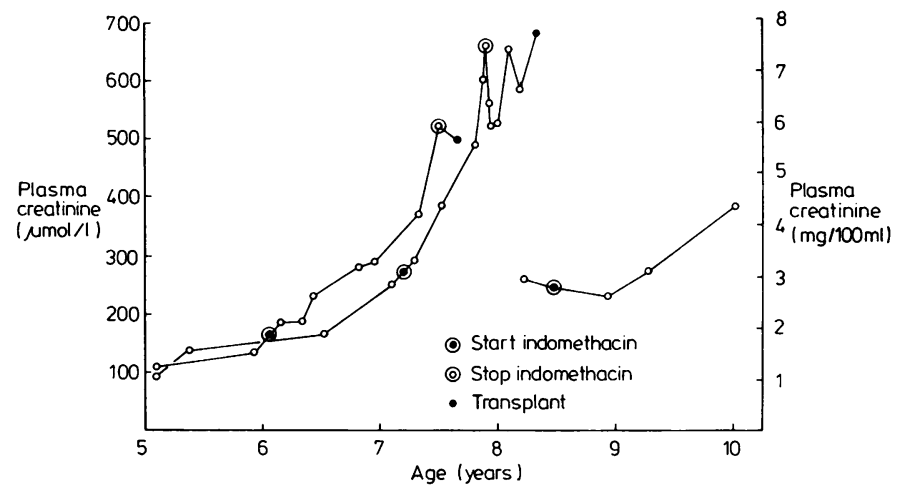

Fig. 4 Plasma creatinine concentrations before, during, and after indomethacin treatment.

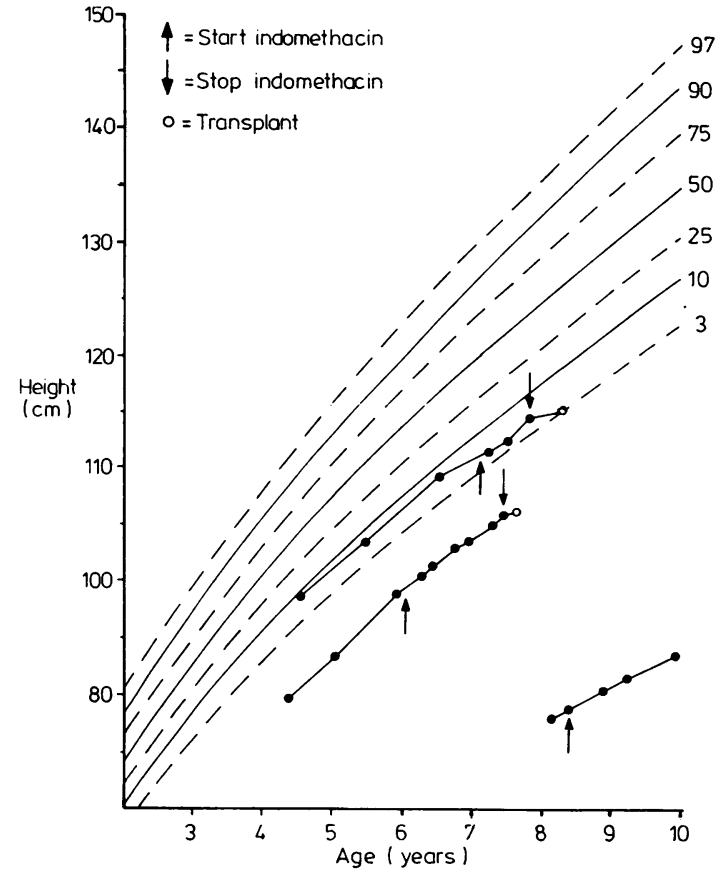

Fig. 5 Linear growth of the 3 patients in relation to indomethacin therapy.

\section{Discussion}

Children with nephropathic cystinosis suffer growth failure, polyuria and polydipsia, hypophosphataemic rickets, and chronic electrolytic imbalance ${ }^{16}$; these features are due, at least in part, to the presence of the renal Fanconi syndrome. Partial correction of the metabolic abnormalities may be achieved with supplements of salt, alkali, potassium, and phosphate; however, in at least some patients such attempts at replacement therapy may be selfdefeating, since the volume expansion induced by the extra salt reduces tubular reabsorption, not only of sodium, but also of glucose, bicarbonate, and phosphate, thus actually worsening the situation. ${ }^{17}$

The physiological role of prostaglandins in the control of nephronal function is not yet clear, and contradictory reports have appeared with regard to their effects. ${ }^{1819}$ However, inhibition of prostaglandin synthetase with indomethacin consistently reduces renal blood flow and GFR and enhances tubular sodium reabsorption..$^{20}$ This effect has been demonstrated in Bartter's syndrome, ${ }^{11}$ diuretic abuse, ${ }^{12}$ renal tubular acidosis, ${ }^{14}$ and in newborn infants with patent ductus arteriosus. ${ }^{13}$ The first reported use of indomethacin in cystinosis was by Bétend et al. ${ }^{21}$ who demonstrated a reduction in polyuria, improvement in plasma electrolyte values, and growth enhancement; the beneficial effect on polyuria was confirmed in 2 further patients by Lemire and Kaplan. ${ }^{22}$ Proesmans et al ${ }^{23}$ obtained similar results and showed the reduced urine volume to be associated with reduced free water clearance. The present study was undertaken to investigate in more detail the effect of indomethacin on renal function, particularly renal sodium and water handling, and on the clinical progress of the disease.

The acute effect on GFR was clear and similar to that described in other conditions. The fact that saline volume expansion reversed the fall supports the view that the effect on GFR is secondary to a haemodynamic change; this would be entirely consistent with the assumption that renal prostaglandins are glomerular vasodilators. As regards the long-term effect on glomerular function, our data do not permit a firm conclusion to be drawn. In one of the 2 children in whom indomethacin was stopped there was a substantial subsequent fall in plasma 
creatinine, suggesting that reversible glomerular vasoconstriction persisted throughout treatment. The general trend shown by all 3 patients is similar to that seen in untreated children, and there is no evidence that the drug accelerates their inevitable decline into end stage renal failure.

The method used to investigate tubular sodium handling relies for its validity on the assumption that 'solute-free water' is generated in the distal tubule by reabsorption of sodium (with an attendant anion) without water; hence the need for water diuresis to suppress antidiuretic hormone. The distinction between proximal and distal tubule made in this way is functional rather than anatomical, the two segments meeting at the point in the ascending limb of the loop of Henle at which the tubular fluid is isotonic with respect to plasma, presumably near the corticomedullary boundary. Thus the proximal tubule, as defined in this way, includes the loop.

Analysis of tubular reabsorption of salt and water (Figs 1 and 2) shows that both proximal and distal nephron segments reabsorb a larger fraction of the sodium presented to them under the influence of indomethacin than under control conditions. The reduction in sodium delivery to the distal tubule leads to diminished tubular sodium-potassium exchange, which is probably the major cause of the hypokalaemia characteristic of the disease, and to relief of polyuria and salt wasting. These effects could be mediated in at least three ways: (1) by enhancing sodium transport in proximal convoluted tubule, (2) by increasing active chloride reabsorption in the ascending limb of the loop, or (3) by a haemodynamic change alone, modifying the Starling forces in the peritubular capillaries, which are known to affect the rate of fluid reabsorption in the proximal convoluted tubule. ${ }^{24}$ Glomerular vasoconstriction would reduce peritubular capillary hydrostatic pressure, altering the balance of forces in the required direction. Thus it is possible to explain the observed effect of indomethacin on both GFR and sodium reabsorption without necessarily having to postulate an action of the drug (or of prostaglandins) on sodium transport per se.

Formal tests of tubular reabsorption of glucose, bicarbonate, and other substances wasted in the Fanconi syndrome were not done, partly because both glucose and bicarbonate titration studies are dangerous in hypokalaemic subjects and partly because of the ordeal for the children. Nevertheless, the rise in plasma bicarbonate and phosphate concentrations in Case 3 suggest that reabsorption was enhanced. There are grounds for expecting this to happen, in that factors such as extracellular fluid volume which affect proximal tubular sodium reabsorption also affect the renal threshold for these other substances.

The lack of obvious growth enhancement is disappointing. Given that the children were already in quite severe renal failure, it may be that their growth was better that it would have been without treatment. More extended studies on children at an earlier stage of the disease will be needed to settle this point. The general clinical benefits of treatment, however, were striking. Relief of polyuria and polydipsia led to one child (Case 1) sleeping through the night, having previously risen up to 6 times nightly to pass urine. Despite the experimental nature of the treatment and its risks (see below), all parents wished to continue treatment when the studies were completed. Since the investigation was performed, several more children with cystinosis $\vec{N}$ have been treated with indomethacin, with marked clinical benefit in all cases. Improvement in appetite, $\rightarrow$ energy, and general wellbeing, in addition to $\frac{\text { 의 }}{2}$ reduction in urine volume, were the effects most commonly commented upon by the families of these children.

A fourth child, treated but not included in the clearance studies, suffered a duodenal perforation which was successfully treated in another hospital However, he had complained of dyspeptic symptoms for some time before the emergency, and this was not brought to medical attention. Since this evers we have taken pains to stress to parents the importance of such symptoms, and the advisability of giving the drug on a full stomach: no further side effects have been encountered.

We conclude that, in children with nephropathic $\overrightarrow{\vec{D}}$ cystinosis who are not well controlled on $\frac{0}{3}$ conventional treatment, indomethacin produces $\vec{\partial}$ significant clinical and biochemical improvement and is a beneficial adjunct to therapy. A useful effect on growth however, has not yet been demonstrated.

We thank the children and their parents for their patience, forbearance, and co-operation during this study; Miss Ann Chapman for typing the manuscript.

\section{References}

1 Hambraeus L, Broberger O. Penicillamine treatment of cystinosis. Acta Paediatr Scand 1967; 56: 243-8.

2 Schmidt H, Lutz P, Bickel H. Wertbeurteilving der $\sigma$ diätetischen Behandlung der Cystinose. Monatsschr $\mathrm{N}$ Kinderheilkd 1973; 121: 171-3.

3 Schneider J A, Schlesselman J J, Mendoza S A, et al. W Ineffectiveness of ascorbic acid therapy in nephropathic cystinosis. N Engl J Med 1979; 300: 756-9.

4 Butler J D, Tietze F, Pellefigue F, Spielberg S P, Schulman J D. Depletion of cystine in cystinotic fibro- of blasts by drugs enclosed in liposomes. Pediatr Res 1978; 12: 46-51. 
5 Roy L P, Pollard A C. Letter: Cysteamine therapy for cystinosis. Lancet 1978 ; ii: 729-30.

- Girardin E P, DeWolfe M S, Crocker J F S. Treatment of cystinosis with cysteamine. J Pediatr 1979; 94: 838-40.

7 Yudkoff M, Foreman J W, Segal S. Effects of cysteamine therapy in nephropathic cystinosis. $N$ Engl J Med 1981; 304: 141-5.

8 Thoene J G, Lemons R. Cystine depletion of cystinotic tissues by phosphocysteamine (WR 638). J Pediatr 1980; 96: 1043-4.

9 Etches P, Pickering D, Smith R. Cystinotic rickets treated with vitamin D metabolites. Arch Dis Child 1977; 52: 661-4.

10 Gertner J M, Brenton D P, Dent C E, Domenech M. Treatment of the rickets of cystinosis with 1-alphahydroxycholecalciferol. Calcif Tissue Res 1977; 22: Supplement, 63-7.

11 Verberckmoes R, van Damme B, Clement J, Amery A, Michielsen P. Bartter's syndrome with hyperplasia of renomedullary cells; successful treatment with indomethacin. Kidney Int 1976; 9: 302-7.

12 Patak R V, Mookerjee B K, Bentzel C J, Hysert P E, Babej M, Lee J B. Antagonism of the effects of furosemide by indomethacin in normal and hypertensive man. Prostaglandins 1975 ; 10: 649-59.

13 Cifuentes $R$ F, Olley $P$ M, Balfe J W, Radde I C, Soldin S J. Indomethacin and renal function in premature infants with persistent patent ductus arteriosus. $J$ Pediatr 1979; 95: 583-7.

14 Caruana R J, Buckalew V M. Improvement of hypercalciuria, potassium wasting, and hyperreninemia in incomplete distal renal tubular acidosis by indomethacin. Nephron 1979; 24: 232-5.

15 Heyrovsky A. A new method for the determination of inulin in plasma and urine. Clin Chim Acta 1956; 1: 470-3.
${ }^{16}$ Schneider J A, Schulman J D. Cystinosis: a review. Metabolism 1977; 26: 817-39.

17 Arant B S, Greifer I, Edelmann C M, Jr, Spitzer A. Effect of chronic salt and water loading on the tubular defects of a child with Fanconi syndrome (cystinosis). Pediatrics 1976; 58: 370-7.

18 McGiff J C, Crowshaw K, Itzkovitz H D. Prostaglandins and renal function. Fed Proc 1974; 33: 39-47.

19 Hill T W K, Moncada S. The renal haemodynamic and excretory actions of prostacyclin and 6-oxo-PGF $1 \alpha$ in anaesthetized dogs. Prostaglandins 1979; 17: 87-98.

20 Donker A J M, Arisz L, Brentjens J R H, van der Hem G K, Hollemans H J G. The effect of indomethacin on kidney function and plasma renin activity in man. Nephron 1976; 17: 288-96.

21 Bétend B, David L, Vincent M, Hermier M, François R. Successful indomethacin treatment of two paediatric patients with severe tubulopathies: a boy with an unusual hypercalciuria and a girl with cystinosis. Helv Paediatr Acta 1979; 34: 339-44.

${ }^{22}$ Lemire J, Kaplan B S. Prolonged use of indomethacin in cystinosis (abstract). Pediatr Res 1981; 15 : 696.

23 Proesmans W, Snoeck L, Kyele Akumola Sina J, Van Aerde J, Eeckels R. Inhibitors of prostaglandin synthetase as a therapy for cystinosis (abstract). Int J Pediatr Nephrol $1981 ; 2: 130$.

24 Earley L, Schrier R. Intrarenal control of sodium excretion by haemodynamic and physical factors. In: Orloff $\mathbf{J}$, Berliner R W, eds. Handbook of physiology. Section 8. Renal physiology. Washington DC: American Physiological Society, 1973: 677-720.

Correspondence to Dr G B Haycock, 9th floor, Guy's Tower, Guy's Hospital, St Thomas Street, London SE1 9RT.

Received 16 August 1982 